\title{
The effects of body mass index and body shape perceptions of South Korean adults on weight control behaviors; Correlation with quality of sleep and residence of place
}

\author{
Nam E Kang', Seung Ju Kim², Yoon Sin $\mathrm{Oh}^{15}$ and Se-Eun Jang ${ }^{15}$ \\ ${ }^{1}$ Department of Food and Nutrition, Eulji University, 553, Sanseong-daero, Seongnam, Gyeonggi 13135, Republic of Korea \\ ${ }^{2}$ Department of Nursing, Eulji University, 553, Sanseong-daero, Seongnam, Gyeonggi 13135, Republic of Korea
}

BACKGROUND/OBJECTIVES: The obese population is rapidly increasing because of reduced physical activity and a Westernized diet; consequently, various chronic diseases are more prevalent. With the increasing interest in body shape and appearance, research on body shape perceptions and accompanying weight control behaviors are needed for healthy weight management. SUBJECTS/METHODS: A cross-sectional survey was conducted on randomly selected 536 (209 men and 327 women) aged 20 to 65 years. Body mass index (BMI), body-shape perception, weight control behavior, quality of sleep, and place of residence were collected using self-reported questionnaires. Multivariable logistic regression analysis was conducted using complex design in each groups. Collected data were analyzed using the SAS 9.4 statistical package, and the significance level was set at $P<0.05$.

RESULTS: When these two variables were divided into four groups, they were found to influence dieting attempts. People with abnormal weights who were dissatisfied with their body shapes attempted dieting 5.23 times more than those with healthy weights and satisfaction with their body shapes. Further, those with normal weights but dissatisfaction with their bodies attempted dieting 4.45 times more than those who were satisfied with their shapes. Subjects in their 20 s attempted dieting 2.53 times more than those in their $30 \mathrm{~s}$ and $40 \mathrm{~s}$, and female subjects attempted dieting 2.24 times more than male subjects.

CONCLUSIONS: A correct perception of one's shape can be an important factor for dietary behavior, as body shape perceptions and dieting attempts are strongly related. Additionally, healthy weight management and nutrition education are important elements to incorporate into a weight control program aimed at preventing excessive weight control behaviors and promoting correct perceptions of body shape.

Nutrition Research and Practice 2020;14(2):160-166; https://doi.org/10.4162/nrp.2020.14.2.160; plSSN 1976-1457 elSSN 2005-6168

Keywords: Body image, BMl, body weight maintenance, health education

\section{INTRODUCTION}

Rapid industrial development and improved economic levels, along with reduced physical activity and Westernized dietary patterns, are fostering an increase in the obese population [1]. According to 2016 National Health Statistics, the obesity rate among adult men and women has been increasing steadily over the past decade. Especially, the severely obese population (with a body mass index, or BMl, of 30 or above) has been reported as $26 \%$-higher than the OECD average (25.6\%) [2]. Socioeconomic losses resulting from obesity were assessed at KRW 9.2 trillion in 2015, a twofold increase over the past decade. Costs are expected to accelerate because of such factors as aging [2]. Various chronic diseases, including obesity, diabetes, hypertension, cardiovascular diseases, and cancer, are associated with an overweight condition [3,4], and an underweight condition is linked to an increase in malnutrition, pulmonary diseases, digestive diseases, and osteoporosis [5,6]. Additionally, mortality from these conditions is on the rise. Accordingly, maintaining proper weight is very important for reducing the likelihood of disease and related costs and supporting a healthy and longer life.

To maintain proper weight, assessments of environmental and genetic factors that cause energy imbalance are necessary. An appropriate perception of one's weight, efforts to lose weight, the weight loss method, and an analysis of related factors can be used as evidence for suggesting medical, clinical, and nutritional treatments necessary for healthy weight management.

Physical appearance has become a very important means of

\footnotetext{
This work was supported by the National Research Foundation of Korea (NRF) grant funded by the Korea government (MSIP; Ministry of Science, ICT \& Future Planning) (No. NRF-2017R1C1B5077047, NRF-2018R1C1B6000998).

${ }^{\S}$ Corresponding Authors: Yoon Sin Oh, Tel. 82-31-740-7287, Fax. 82-31-740-7370, Email. ysoh@eulji.ac.kr Se-Eun Jang, Tel. 82-31-740-7368, Fax. 82-31-740-7370, Email. sejang@eulji.ac.kr

Received: June 16, 2019, Revised: August 13, 2019, Accepted: December 17, 2019

This is an Open Access article distributed under the terms of the Creative Commons Attribution Non-Commercial License (http://creativecommons.org/licenses/by-nc/3.0/) which permits unrestricted non-commercial use, distribution, and reproduction in any medium, provided the original work is properly cited.
} 
expressing oneself in modern society. As interest in women's diets-for those who want slim figures-is increasing with the current focus on physical appearance, maintaining a proper weight is becoming difficult. A study regarding the weight control behaviors of college students in 20 countries reported that South Korean female college students are determined to lose weight though often underweight [7]. According to a study by Kim et al., [8] 47.5\% of female college students considered themselves obese, although the actual obesity rate was only $4 \%$. Further, $86.2 \%$ of the students responded that they needed to lose weight despite normal weight levels. The studies cited above, like most previous studies on body shape perceptions, focused on female college students, and research on body shape perceptions of the elderly is lacking. Accordingly, research on body shape perception by age, gender, and weight control behavior is necessary to develop appropriate nutrition education for healthy weight control.

Results of an analysis of subjective body shape perceptions from the Korea National Health and Nutrition Examination Survey administered from 2001 to 2014 showed that incorrect perceptions of body shape tended to increase as age and body weight increased, and efforts to lose weight also tended to escalate as body weight increased [9]. An analysis of interactions with environmental factors was difficult, however, because attitudes toward weight control and the changing patterns of health-related lifestyle habits based on body shape perceptions were not evaluated in the survey.

Weight is closely related to individual lifestyle, economic level, social status, behavior and dietary patterns influence overweight [10]. Moreover, sleep quality was considered as an important factors of intervention program for prevention and management of obesity $[11,12]$. Therefore, in this study, weight control attitudes, health-related lifestyle habits, sleep quality, economic level, and dietary habits of male and female adults residing in the metropolitan and non-metropolitan area were examined according to body shape perceptions and degree of obesity by age. Then, the basis for desirable dietary behavior and systematic nutrition education aimed at maintaining proper weight was proposed.

\section{SUBJECTS AND METHODS}

\section{Subjects and duration}

A survey of adults aged 20 to 65 years who were residing in the metropolitan and non-metropolitan area was conducted. The participants were selected on a random basis after taking their voluntary approval. The total number of participants, excluding those whose responses were incomplete, was 536 (209 males, 327 females). The survey was conducted from November 1, 2018, to December 31, 2019. The present study was conducted after obtaining approval (IRB No. EUIRB 2018-111) from the Institutional Review Board (IRB) of Eulji University.

\section{Content and scope of the survey}

Existing literature was consulted for developing the questionnaire administered in the present study that inquired about general items, physical measurements, type of residence, perception of one's body shape, weight control, and lifestyle habits (activity level, exercise, frequency of dining out, and sleep quality). The questionnaire was used after dissemination of a preliminary survey and supplementation. Age, type of job, place of residence, and economic level were used as sociodemographic factors. Age categories were 20-29 years, 30-39 years, 40-49 years, 50-59 years, and 60 years or older. Jobs categories were student, blue-collar worker, white-collar worker, and unemployed. Place of residence referred to the metropolitan and non-metropolitan area. Economic levels were as follows: affluent, somewhat affluent, average, somewhat difficult, and very difficult. Categories for subjective body shape perception were dissatisfaction and satisfaction. Using a BMI measurement calculated from one's height and weight, body weight was categorized as either normal $\left(18.5 \mathrm{~kg} / \mathrm{m}^{2} \leq \mathrm{BMl} \leq 23.0 \mathrm{~kg} / \mathrm{m}^{2}\right)$ or abnormal $\left(B M I \leq 18.5 \mathrm{~kg} / \mathrm{m}^{2}\right.$ or $B M l \geq 23.0 \mathrm{~kg} / \mathrm{m}^{2}$ ) [13]. Weight control was categorized according to the frequency of participants' dieting experiences (i.e., have been on a diet, diets sometimes, has never been on a diet). Categories for frequency of eating out were: almost never, 1-2 times/week, 3-4 times/week, 5 or more times/week. Subjective health status was categorized as "good" (i.e., healthy/no disease, relatively healthy, though with occasional body aches and fever), and "poor" (i.e., no specific disease but tired and somewhat weak or currently diagnosed with a disease). Daily activity level was categorized as low (very light activity), moderate (average level of physical activity and exercise), and high (intense or extreme activity).

\section{Data processing and statistical analysis}

All statistical analyses were performed using SAS statistical software version 9.4 (SAS Institute, Cary, NC, USA). A P-value $<0.05$ was considered to indicate a statistically significant difference. The distribution of each categorical variable was examined by an analysis of frequencies and percentages, and $\mathrm{X}^{2}$ tests were performed. T-test dla was also performed for continuous variables to compare mean and standard deviation values. A number of binary logistic regression analyses were performed to determine the influence of BMI and body shape perception on weight control behaviors. The independent variables were BMI and body shape perception, and the dependent variable was the weight control behavior experience. Influence was determined by the odds ratio (OR) of the dependent variable according to the independent variable categories.

\section{RESULTS}

Characteristics of subjects' general characteristics based on weight status

A general characteristics of the subjects according to weight status is presented in Table 1. Males comprised $38.99 \%$ of the sample, and female subjects accounted for $61.01 \%$, Most participants were aged 20-29 years (62.13\%). Additionally, most participants were students (54.29\%), and a higher proportion of the subjects $(65.1 \%)$ lived outside the metropolitan area. The economic level applicable to the majority of subjects (65.1\%) was average (i.e., moderate). Further, $53.4 \%$ of the participants reported that their sleep quality was "good" (slightly higher 
than those who regarded their sleep quality as "bad"). A high level of daily activity (i.e., exercise) was predominant $(41.0 \%)$, followed by low (31.2\%) and average (27.8\%) activity levels. In terms of eating out, the most frequent response was 1-2 times per week (37.7\%). Regarding individuals' perceived health status, $49.25 \%$ of the subjects responded "good" and $50.8 \%$ responded "bad."

\section{Relation of BMI and body shape perception}

The relation of body shape perception according to BMl is presented in Table 1. The average BMl of the participants in the survey was within normal limits $\left(22.49 \mathrm{~kg} / \mathrm{m}^{2}\right)$. The analysis of body shape perceptions according to BMl showed that $22.76 \%$ of the participants, including $73(13.6 \%)$ participants with normal BMls and $49(9.1 \%)$ with abnormal BMls, were satisfied with their body shapes, whereas $77.2 \%-223$ subjects (41.6\%) with normal BMls and 191 (35.6\%) with abnormal BMls-were dissatisfied with their body shapes.

Relation of BMI, body shape perception, and weight control behavior
The weight control behaviors based on BMl and body shape perception showed that when participants were satisfied with their body shapes, they typically did not engage in weight control behaviors, unlike those who were dissatisfied with their body shapes regardless of BMl level. Study participants responded that they engaged in weight control behaviors-regardless of BMI level-when they were dissatisfied with their body shapes. An analysis of weight control behavior by age showed that more subjects engaged in weight control behaviors compared to those who did not for all age groups; furthermore, $76.28 \%$ of participants in their 20s responded that they engaged in weight control behaviors. The analysis of weight control behavior by gender showed a higher frequency for males and females engaging in such behavior than those who did not, and $74.31 \%$ of female participants responded that they made efforts to control their weight (Table 1).

A logistic regression analysis was performed to determine relations between satisfaction with body shape and weight control behavior (Table 2). For the analysis, body shape satisfaction, according to BMl, was set as the variable of interest, and weight control behavior was set as the dependent variable.

Table 1. General characteristics of participants $(n=536)$

\begin{tabular}{|c|c|c|c|c|c|c|}
\hline \multirow{2}{*}{\multicolumn{2}{|c|}{ Variables }} & \multicolumn{2}{|c|}{ Weight control behavior } & \multirow{3}{*}{$\begin{array}{c}\text { Total } \\
191 \text { (35.63) }\end{array}$} & \multirow{3}{*}{$\frac{x^{2} / t}{84.06}$} & \multirow{3}{*}{$\begin{array}{r}P \text {-value } \\
<0.0001\end{array}$} \\
\hline & & \multirow{2}{*}{$\frac{\text { Yes }}{160(83.77)}$} & \multirow{2}{*}{$\frac{\text { No }}{31(16.23)}$} & & & \\
\hline Disparity in physical satisfaction & Unsatisfied-abnormal BMI (UA) & & & & & \\
\hline & Unsatisfied-normal BMI (UN) & $172(77.13)$ & $51(22.87)$ & $223(41.60)$ & & \\
\hline & Satisfied-abnormal BMI (SA) & $19(38.78)$ & $30(61.22)$ & 49 (9.14) & & \\
\hline & Satisfied-normal BMI (SN) & 27 (36.99) & $46(63.01)$ & $73(13.62)$ & & \\
\hline BMl $\left(\mathrm{kg} / \mathrm{m}^{2}\right)$ & & $22.87 \pm 3.3 .4$ & $21.58 \pm 4.19$ & $22.49 \pm 3.66$ & 3.78 & 0.0002 \\
\hline \multirow[t]{3}{*}{ Age group (\%) } & $20 \mathrm{~s}$ & $254(76.28)$ & $79(23.72)$ & $333(62.13)$ & 14.72 & 0.0006 \\
\hline & $30-40 \mathrm{~s}$ & 78 (59.09) & $54(40.91)$ & $132(24.63)$ & & \\
\hline & $\geq 50 \mathrm{~s}$ & $46(64.79)$ & $25(35.21)$ & $71(13.25)$ & & \\
\hline \multirow[t]{2}{*}{ Sex (\%) } & Male & $135(64.59)$ & $74(35.41)$ & 209 (38.99) & 5.34 & 0.0209 \\
\hline & Female & $243(74.31)$ & $84(25.69)$ & $327(61.01)$ & & \\
\hline \multirow[t]{4}{*}{ Job (\%) } & Student & $221(75.95)$ & $70(24.05)$ & $291(54.29)$ & 9.48 & 0.0236 \\
\hline & Not-working & $44(63.77)$ & $25(36.23)$ & $69(12.87)$ & & \\
\hline & Blue-collar worker & $56(66.67)$ & $28(33.33)$ & $84(15.67)$ & & \\
\hline & White-collar worker & 57 (61.96) & $35(38.04)$ & 92 (17.16) & & \\
\hline \multirow[t]{2}{*}{ Residual (\%) } & Metropolitan & $136(72.73)$ & $51(27.27)$ & 187 (34.89) & 0.52 & 0.4714 \\
\hline & non-metropolitan & $242(69.34)$ & 107 (30.66) & $349(65.11)$ & & \\
\hline \multirow[t]{3}{*}{ Perceived economic status (\%) } & Low & $40(74.07)$ & $14(25.93)$ & $54(10.07)$ & 0.57 & 0.7515 \\
\hline & Moderate & $230(69.49)$ & 101 (30.66) & $349(65.11)$ & & \\
\hline & High & $108(71.52)$ & $43(28.48)$ & $151(28.17)$ & & \\
\hline \multirow[t]{2}{*}{ Sleep quality (\%) } & Bad & $188(75.20)$ & $62(24.80)$ & $250(46.64)$ & 4.52 & 0.0335 \\
\hline & Good & $190(66.43)$ & $96(33.57)$ & $286(53.36)$ & & \\
\hline \multirow[t]{3}{*}{ Exercise (\%) } & Low & $120(71.86)$ & $47(28.14)$ & 167 (31.16) & 0.46 & 0.7927 \\
\hline & Moderate & $102(68.46)$ & $47(31.54)$ & $149(27.80)$ & & \\
\hline & High & $156(70.91)$ & $64(29.09)$ & $220(41.04)$ & & \\
\hline \multirow[t]{4}{*}{ Number of times to eat out (\%) } & 1-2/week & $136(67.33)$ & $66(32.67)$ & 202 (37.69) & 5.32 & 0.1501 \\
\hline & 3-4/week & $129(75.00)$ & $43(25.00)$ & $172(32.09)$ & & \\
\hline & 5-/week & $75(74.26)$ & $26(25.74)$ & $101(18.84)$ & & \\
\hline & None & $38(62.30)$ & $23(37.70)$ & $61(11.38)$ & & \\
\hline \multirow[t]{2}{*}{ Perceived health status (\%) } & Bad & $201(73.90)$ & $71(26.10)$ & $272(50.75)$ & 2.70 & 0.1001 \\
\hline & Good & 177 (67.05) & 87 (32.95) & $264(49.25)$ & & \\
\hline Total (\%) & & & & $536(100)$ & & \\
\hline
\end{tabular}

Values are expressed as means $\pm \mathrm{SD}$ or $\mathrm{n}(\%)$ 
Table 2. The association between disparity in percided body satisfaction and weight control behavior

\begin{tabular}{|c|c|c|c|c|}
\hline & & \multirow{2}{*}{ OR } & \multicolumn{2}{|c|}{$95 \% \mathrm{Cl}$ for $\mathrm{OR}$} \\
\hline & & & Lower & Upper \\
\hline \multirow[t]{4}{*}{ Disparity in physical satisfaction and BMI } & Unsatisfied-abnormal BMI (UA) & 5.23 & 2.52 & 10.85 \\
\hline & Unsatisfied-normal BMI (UN) & 4.45 & 2.37 & 8.35 \\
\hline & Satisfied-abnormal BMI (SA) & 0.69 & 0.30 & 1.59 \\
\hline & Satisfied-normal BMI (SN) & 1.00 & - & - \\
\hline BMI & & 1.24 & 1.12 & 1.38 \\
\hline \multirow[t]{3}{*}{ Age } & $20-29$ & 2.53 & 1.09 & 5.85 \\
\hline & $30-49$ & 1.00 & - & - \\
\hline & $\geq 50$ & 1.29 & 0.64 & 2.58 \\
\hline \multirow[t]{2}{*}{ Sex } & Male & 1.00 & - & - \\
\hline & Female & 2.24 & 1.33 & 3.78 \\
\hline \multirow[t]{4}{*}{ Job } & Student & 1.32 & 0.54 & 3.25 \\
\hline & Not-working & 1.27 & 0.58 & 2.75 \\
\hline & Blue-collar worker & 0.93 & 0.45 & 1.94 \\
\hline & White-collar worker & 1.0 & - & - \\
\hline \multirow[t]{2}{*}{ Residual } & Metropolitan & 0.93 & 0.45 & 1.94 \\
\hline & non-metropolitan & 1.0 & - & - \\
\hline \multirow[t]{3}{*}{ Perceived economic status } & Low & 1.03 & 0.48 & 2.19 \\
\hline & Moderate & 1.0 & - & - \\
\hline & High & 1.25 & 0.73 & 2.14 \\
\hline \multirow[t]{2}{*}{ Sleep quality } & Bad & 1.46 & 0.94 & 2.26 \\
\hline & Good & 1.0 & - & - \\
\hline \multirow[t]{3}{*}{ Exercise } & Low & 1.25 & 0.73 & 2.14 \\
\hline & Moderate & 1.24 & 0.71 & 2.17 \\
\hline & High & 1.0 & - & - \\
\hline \multirow[t]{4}{*}{ Number of times to eat out } & 1-2/week & 1.14 & 0.56 & 2.31 \\
\hline & 3-4/week & 1.52 & 0.72 & 3.20 \\
\hline & 5-/week & 1.42 & 0.62 & 3.25 \\
\hline & None & 1.0 & - & - \\
\hline \multirow[t]{2}{*}{ Perceived health status } & Bad & 1.0 & - & - \\
\hline & Good & 1.25 & 0.79 & 1.98 \\
\hline
\end{tabular}

OR, odds ration; $\mathrm{Cl}$, confidence interval; $\mathrm{BMl}$, body mass index.

Participants whose BMls were abnormal and who were dissatisfied with their body shapes (UA) engaged in weight control behaviors 5.23 times more than those whose BMls were normal and who were satisfied with their body shapes (SN), whereas participants with normal BMls but dissatisfaction with their body shapes (UN) engaged in weight control behaviors 4.45 times more. Participants in their 20 s engaged in weight control behaviors 2.53 times more than participants in their 30s and 40s. In addition, female participants engaged in weight control behaviors 2.24 times more than male participants (Table 2).

Relation between body shape perception and weight control behavior by age, quality of sleep, and place of residence

The relation between body shape perception and weight control behavior by age revealed that participants in their 20s who were dissatisfied with their body shapes-regardless of $\mathrm{BMl}$-were found to engage in weight control behaviors 3 times or more than the SN group. Further, the OR for participants in their 30s and 40s who were dissatisfied with their shapes was 5 or more (cross ratio) (Table 3 ).

An analysis of body shape perceptions and weight control behaviors based on quality of sleep showed that many participants were dissatisfied with their body shapes, regardless of BMl, when their sleep quality was not good. Additionally, they engaged in weight control behaviors at a significantly greater rate compared to participants with the SN group. The UN group is a participant who has experienced "bad" sleep quality and the OR for weight control behavior is 3.75. The OR of the UA group with "bad" sleep quality is 13.1 (Table 3). On the other hand, the results of the SN group were similar regardless of whether the quality of sleep was "good" or "bad". The UN group with "good" sleep quality had a higher OR than the UA group. Therefore, weight control behavior was determined to be affected by the quality of sleep.

The analysis of body shape perceptions and weight control behaviors according to place of residence showed that participants residing in metropolitan (Seoul) who were dissatisfied with their body shapes, regardless of $\mathrm{BMI}$, engaged in weight control behaviors 13 times or more than SN group residing in metropolitan (Seoul). On the other hand, participants residing in the metropolitan area who were dissatisfied with their body shapes, regardless of $\mathrm{BMI}$, engaged in weight control behaviors 3 times or more than the SN group (Table 3). Therefore, the influence of the place of residence on weight control behavior was 
Table 3. The association between disparity in percided body satisfaction and weight control behavior by age, sleep quality and residual

\begin{tabular}{|c|c|c|c|c|}
\hline & & \multirow{2}{*}{ OR } & \multicolumn{2}{|c|}{$95 \% \mathrm{Cl}$ for $\mathrm{OR}$} \\
\hline & & & Lower & Upper \\
\hline \multicolumn{5}{|l|}{ Age $(20-29)$} \\
\hline \multirow[t]{4}{*}{ Disparity in physical satisfaction and BMI } & Unsatisfied-abnormal BMI (UA) & 3.03 & 1.16 & 7.87 \\
\hline & Unsatisfied-normal BMI (UN) & 3.21 & 1.39 & 7.45 \\
\hline & Satisfied-abnormal BMI (SA) & 0.38 & 0.12 & 1.14 \\
\hline & Satisfied-normal BMI (SN) & 1.0 & - & - \\
\hline \multicolumn{5}{|l|}{ Age $(30-49)$} \\
\hline \multirow[t]{4}{*}{ Disparity in physical satisfaction and BMI } & Unsatisfied-abnormal BMI (UA) & 11.50 & 2.47 & 53.59 \\
\hline & Unsatisfied-normal BMI (UN) & 5.77 & 1.37 & 24.27 \\
\hline & Satisfied-abnormal BMI (SA) & 1.70 & 0.27 & 10.58 \\
\hline & Satisfied-normal BMI (SN) & 1.0 & - & - \\
\hline \multicolumn{5}{|l|}{ Age $(\geq 50)$} \\
\hline \multirow[t]{4}{*}{ Disparity in physical satisfaction and BMI } & Unsatisfied-abnormal BMI (UA) & 10.77 & 0.78 & 148.39 \\
\hline & Unsatisfied-normal BMI (UN) & 5.95 & 0.64 & 55.42 \\
\hline & Satisfied-abnormal BMI (SA) & 0.53 & 0.02 & 17.10 \\
\hline & Satisfied-normal BMI (SN) & 1.0 & - & - \\
\hline \multicolumn{5}{|l|}{ Sleep quality, bad } \\
\hline \multirow[t]{4}{*}{ Disparity in physical satisfaction and BMI } & Unsatisfied-abnormal BMI (UA) & 13.10 & 3.12 & 55.06 \\
\hline & Unsatisfied-normal BMI (UN) & 3.75 & 1.23 & 11.45 \\
\hline & Satisfied-abnormal BMI (SA) & 0.72 & 0.18 & 2.94 \\
\hline & Satisfied-normal BMI (SN) & 1.0 & - & - \\
\hline \multicolumn{5}{|l|}{ Sleep quality, good } \\
\hline \multirow[t]{4}{*}{ Disparity in physical satisfaction and BMI } & Unsatisfied-abnormal BMI (UA) & 3.71 & 1.50 & 9.17 \\
\hline & Unsatisfied-normal BMI (UN) & 5.46 & 2.39 & 12.45 \\
\hline & Satisfied-abnormal BMI (SA) & 0.48 & 0.16 & 1.46 \\
\hline & Satisfied-normal BMI (SN) & 1.0 & - & - \\
\hline \multicolumn{5}{|l|}{ Residual, metropolitan } \\
\hline \multirow[t]{4}{*}{ Disparity in physical satisfaction and BMI } & Unsatisfied-abnormal BMI (UA) & 14.49 & 2.80 & 74.88 \\
\hline & Unsatisfied-normal BMI (UN) & 13.17 & 3.30 & 52.63 \\
\hline & Satisfied-abnormal BMI (SA) & 0.40 & 0.06 & 2.59 \\
\hline & Satisfied-normal BMI (SN) & 1.0 & - & - \\
\hline \multicolumn{5}{|l|}{ Residual, non-metropolitan } \\
\hline \multirow[t]{4}{*}{ Disparity in physical satisfaction and BMI } & Unsatisfied-abnormal BMI (UA) & 4.41 & 1.84 & 10.58 \\
\hline & Unsatisfied-normal BMI (UN) & 3.19 & 1.49 & 6.81 \\
\hline & Satisfied-abnormal BMI (SA) & 0.65 & 0.24 & 1.75 \\
\hline & Satisfied-normal BMI (SN) & 1.0 & - & - \\
\hline
\end{tabular}

$\mathrm{OR}$, odds ration; $\mathrm{Cl}$, confidence interval; $\mathrm{BM}$, body mass index.

confirmed. Specifically, participants who resided in metropolitan and were dissatisfied with their body shapes tended to engage in weight control behaviors to a greater extent than participants who resided in the non-metropolitan area.

\section{DISCUSSION}

Obesity is more than a simple issue regarding appearance; it causes physical problems. In serious cases, it is a chronic disease that requires treatment. Obesity has been associated with diabetes, cardiovascular disease, gallbladder disease, colon cancer, and breast cancer [14,15]. Moreover, many obese women engage in weight control behaviors to prevent diseases caused by obesity, and even non-obese women diet for health reasons [16].

The present study was conducted to understand and analyze weight control behaviors according to BMI and body shape perception. In studies by Kim et al. [17] and Kim et al. [18], about $43.5 \%$ of the subjects correctly perceived their body shapes, whereas about $56.6 \%$ of the subjects perceived their shapes as either fatter or slimmer than their actual body shapes. Additionally, the findings of previous studies in which more subjects were dissatisfied with their shapes-regardless of BMI-were similar to that of the present study. For example, Park et al. [19] reported that $41.7 \%$ of the subjects viewed their shapes as "average," followed by "relatively fat," when asked about their satisfaction with their body shapes (even though their BMls were within normal limits). In fact, $79 \%$ of the subjects wanted to be thinner than they were (Table 1). Subjects assessed their body shapes as fatter or more obese than they were, as seen in the high response rate for "not satisfied" $(41.6 \%)$ to a question in the present study regarding body shape, despite normal BMls. Higher rates of dissatisfaction with body shape were noted, indicating the need for an accurate 
definition of obesity, relevant criteria, and education to inculcate accurate and healthy body images.

Body mass index and self-satisfaction with body shape were set as variables affecting weight control behavior in the present study, and the results confirmed that both factors affect such behaviors (Table 1). The average BMI of the participants who responded that they engaged in weight control behaviors was $22.87 \mathrm{~kg} / \mathrm{m}^{2}$, which was significantly higher than $21.58 \mathrm{~kg} / \mathrm{m}^{2}$ reported for participants who responded that they did not engage in such behaviors. The finding indicates that participants with higher BMls were more sensitive regarding weight control behaviors than their counterparts, which is consistent with the finding of Yang et al. [20], who reported that the higher the $\mathrm{BMl}$, the more the subjects tended to engage in weight control behaviors. In the present study, BMl and satisfaction with body shape were divided into four groups to determine their correlations with weight control behaviors. The results showed that participants who were not satisfied with their body shapes were more sensitive about weight control behaviors, regardless of their BMls, than those with normal BMls and satisfaction with body shape (SN). The OR for participants whose BMls were abnormal and who were dissatisfied with their body shapes (UA) was 5.23. Consequently, the findings of the present study indicate that not only adults' BMls but also satisfaction with body shape are related to weight control behaviors.

In addition, a logistic regression analysis was performed to determine the correlation between weight control behavior, age group, sleep quality, and place of residence according to BMI and satisfaction with body shape. Consequently, the OR by age indicated that participants in their 20s, 30s, and 40s engaged in weight control behaviors if they were dissatisfied with their body shapes, regardless of BMI. Their behaviors contrasted with those of participants with normal BMls and satisfaction with their body shapes (S-N). Kim et al. [21] also suggested that adults who were 50 or older were in need of education-more so than adults in their 20s-40s-about normal $\mathrm{BMl}$ and nutrition. Their study indicated that perceptions of BMI by subjects who were 50 or older were higher than the normal limits.

The OR for participants who responded that their sleep quality was poor and engaged in weight control behaviors was 13.10 and 3.71 times more than those who assessed the quality of their sleep as "good." Ock et al. [22] reported that the shorter the sleep duration, the higher the risk for obesity. In the present study, the OR for weight control behavior differed according to sleep quality for the group with abnormal BMls and dissatisfaction with body shape. These findings can be interpreted as emphasizing the importance of proper sleep as an independent health behavior that is distinct from physical activity and eating habits in the prevention and management of obesity. Based on these findings, future research is needed regarding the optimal sleep duration for reducing the risk of obesity; a prospective study would include various aspects of sleep quality.

Furthermore, a review of differences between metropolitan and non-metropolitan areas revealed that participants in the metropolitan area who were dissatisfied with their body shapes engaged in weight control behaviors, regardless of their BMls; their attempts to control their weight were greater compared to participants with normal BMls and satisfaction with body shape. The results may possibly be explained by the metropolitan area's more frequent exposure to nutrition education through more diverse content and media than in non-metropolitan areas. The findings indicate that nutrition education currently conducted in the metropolitan area should be expanded to non-metropolitan areas.

A correct perception of one's body shape is an important factor for dietary behavior because body shape perception and weight control behaviors are highly related. A correct perception of body shape, regard for the importance of maintaining normal weight, and nutrition education for desirable weight control are necessary for preventing excessive weight control behaviors when perceptions of body shape are incorrect. Additionally, an accompanying weight control program that addresses a correct perception of body shape is necessary.

\section{CONFLICT OF INTEREST}

The authors declare no potential conflicts of interests.

\section{ORCID}

Nam E Kang: https://orcid.org/0000-0002-9374-4580

Seung Ju Kim: https://orcid.org/0000-0003-3308-3802

Yoon Sin Oh: https://orcid.org/0000-0003-3995-4429

Se-Eun Jang: https://orcid.org/0000-0003-3279-0871

\section{REFERENCES}

1. Kang HT, Shim JY, Lee HR, Park BJ, Linton JA, Lee YJ. Trends in prevalence of overweight and obesity in Korean adults, 1998-2009: the Korean National Health and Nutrition Examination Survey. J Epidemiol 2014;24:109-16.

2. Ministry of Health and Welfare. Comprehensive Measures for National Obesity Management (2018 2022). Sejong: Ministry of Health and Welfare; 2018.

3. Jee SH, Yun JE, Park EJ, Cho ER, Park IS, Sull JW, Ohrr H, Samet JM. Body mass index and cancer risk in Korean men and women. Int J Cancer 2008;123:1892-6.

4. Duncan GE, Li SM, Zhou XH. Prevalence and trends of a metabolic syndrome phenotype among U.S. adolescents, 1999-2000. Diabetes Care 2004;27:2438-43.

5. Hannan MT, Felson DT, Dawson-Hughes B, Tucker KL, Cupples LA, Wilson PW, Kiel DP. Risk factors for longitudinal bone loss in elderly men and women: the Framingham Osteoporosis Study. J Bone Miner Res 2000;15:710-20.

6. Suastika K, Dwipayana P, Saraswati MR, Gotera W, Budhiarta AA, Sutanegara ND, Gunadi GN, Nadha KB, Wita W, Rina K, Santoso A, Soegondo S, Kajiwara N, Taniguchi $H$. Underweight is an important risk factor for coronary heart disease in the population of Ceningan Island, Bali. Diab Vasc Dis Res 2012;9:75-7.

7. Wardle J, Haase AM, Steptoe A. Body image and weight control in young adults: international comparisons in university students from 22 countries. Int J Obes 2006;30:644-51.

8. Kim MO, Eun JG, Chang UJ. Recognition of body weight and body part satisfaction in female college students. Korean J Food Nutr 2009;22:205-14. 
9. Lim GE, Kang SY, Kim YK, Kim HY, Park TJ, Kim I, Lee K. Secular trends for body-shape perception, weight-loss efforts, and weight-loss behaviors in Korean adults using the Korea National Health and Nutrition Examination Survey from 2001 to 2014. Korean J Health Promot 2017;17:31-7.

10. Ball K, Mishra GD, Crawford D. Social factors and obesity: an investigation of the role of health behaviours. Int J Obes Relat Metab Disord 2003;27:394-403.

11. Jang MN, Oh SM, Kim HS, Shin HA. The relationship between quality of sleep and body mass index of adolescents: focusing on mediating effect of physical activity, dietary habit, and academic stress and moderating effect of gender. J Korean Public Health Nurs 2019;33:85-97.

12. Cho $\mathrm{KH}$, Cho EH, Hur J, Shin D. Association of sleep duration and obesity according to gender and age in Korean adults: results from the Korea National Health and Nutrition Examination Survey 2007-2015. J Korean Med Sci 2018;33:e345.

13. WHO Expert Consultation. Appropriate body-mass index for Asian populations and its implications for policy and intervention strategies. Lancet 2004;363:157-63.

14. Kim NS, Moon OR, Kang JH, Lee SY, Jeong BG, Lee SJ, Yoon TH, Hwang $\mathrm{KH}$. Increasing prevalence of obesity related disease for Koreans associated with overweight and obesity. Korean J Prev Med 2001;34:309-15.

15. Guh DP, Zhang W, Bansback N, Amarsi Z, Birmingham CL, Anis AH. The incidence of co-morbidities related to obesity and overweight: a systematic review and meta-analysis. BMC Public Health 2009;9:88.

16. Lim YS, Park NR, Jeon SB, Jeong SY, Tserendejid Z, Park HR. Analysis of weight control behaviors by body image perception among korean women in different age groups: using the 2010 Korea National Health and Nutrition Examination Survey data. Korean J Community Nutr 2015;20:141-50.

17. Kim YG. Body image perception, preventive attitude of life-style related and eating behaviors attitude according to obesity level in adult women [master's thesis]. Asan: Soonchunhyang University; 2005.

18. Kim JY. The relationship between health concern related to weight level and weight control behavior in Korean woman [master's thesis]. Seoul: Seoul National University; 2006.

19. Park JY. The BMI, body image recognition, and weight control behavior of female college students. J Korean Acad Fundam Nurs 2011;18:444-51.

20. Yang HY, Byeon YS. Weight control behavior in women college students and factors influencing behavior. J Korean Acad Fundam Nurs 2012;19:190-200.

21. Kim MK, Lee GC. Weight reduction dieting survey and satisfaction degree and diet related knowledge among adult women by age. J Korean Soc Food Sci Nutr 2006;35:572-82.

22. Ock SM, Ju SY, Choi WS, Park HM, Jung Kl, Song CJ. Association of sleep hours with obesity in adult women. Korean J Obes 2008;17:110-6. 